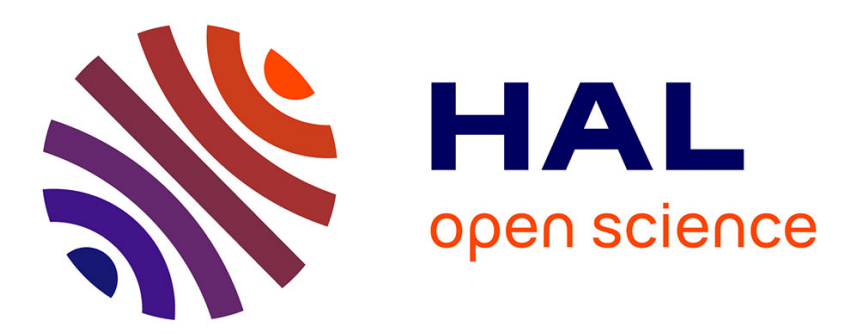

\title{
The Role of Content and Context in PISA Interest Scales - A study of the embedded Interest Items in the PISA 2006 Science Assessment
}

\author{
Barbara Drechsel, Claus Carstensen, Manfred Prenzel
}

\section{- To cite this version:}

Barbara Drechsel, Claus Carstensen, Manfred Prenzel. The Role of Content and Context in PISA Interest Scales - A study of the embedded Interest Items in the PISA 2006 Science Assessment. International Journal of Science Education, 2011, 33 (01), pp.73-95. 10.1080/09500693.2010.518646 . hal-00658172

\section{HAL Id: hal-00658172 \\ https://hal.science/hal-00658172}

Submitted on 10 Jan 2012

HAL is a multi-disciplinary open access archive for the deposit and dissemination of scientific research documents, whether they are published or not. The documents may come from teaching and research institutions in France or abroad, or from public or private research centers.
L'archive ouverte pluridisciplinaire HAL, est destinée au dépôt et à la diffusion de documents scientifiques de niveau recherche, publiés ou non, émanant des établissements d'enseignement et de recherche français ou étrangers, des laboratoires publics ou privés. 


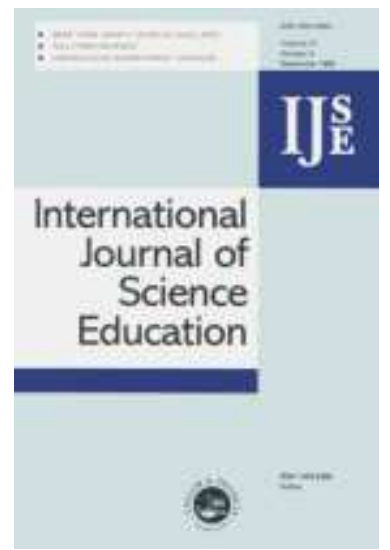

The Role of Content and Context in PISA Interest Scales - A study of the embedded Interest Items in the PISA 2006 Science Assessment

\begin{tabular}{|r|l|}
\hline Journal: & International Journal of Science Education \\
\hline Manuscript ID: & TSED-2010-0328-A \\
\hline Manuscript Type: & Special Issue Research Paper \\
\hline Keywords: & scientific literacy, science interest, large-scale studies \\
\hline Keywords (user): & international comparisons, multidimensional scaling \\
\hline
\end{tabular}

\section{SCHOLARONE ${ }^{\text {m }}$}

Manuscripts 


\title{
The Role of Content and Context in PISA Interest Scales: A Study of the Embedded Interest Items in the PISA 2006 Science Assessment
}

\begin{abstract}
This paper focuses interest in science as one of the attitudinal aspects of scientific literacy. Large-scale data from the Programme for International Student Assessment (PISA) 2006 are analysed in order to describe student interest more precisely. So far the analyses have provided a general indicator of interest, aggregated over all contexts and contents in the science test (Organisation for Economic Co-operation and Development [OECD], 2007a; Prenzel, Schütte, \& Walter, 2007).With its innovative approach PISA embeds interest items within the cognitive test unit and its contents and contexts. The main difference from conventional interest measures is that in most questionnaires, a relatively small number of interest items cover broad fields of contents and contexts. The science units represent a number of systematically differentiated scientific contexts and contents. The units' stimulus texts allow for concrete descriptions of relevant content aspects, applications and contexts.

In the analyses, multidimensional item response models are applied in order to disentangle student interest. The results indicate that multidimensional models fit the data. A two-dimensional model separating interest into two different knowledge of science dimensions described in the PISA science framework is further analysed with respect to gender, performance differences and country. The findings give a comprehensive description of students' interest in science. The paper deals with methodological problems and describes requirements of the test construction for further assessments. The results are discussed with regard to their significance for science education.
\end{abstract}


Recent conceptions of scientific literacy emphasise the multifold facets of this construct. In this sense, scientific literacy includes cognitive as well as motivational and value-related aspects of domain-specific competencies (e.g. Marshall, Scheppler, \& Palmisano, 2002; Millar, 2006). According to this, knowledge and attitudes are seen to be relevant components of scientific literacy in the framework for the Programme for International Student Assessment (PISA) 2006. Interest in science as one of the attitudinal aspects of scientific literacy is the focus of this paper.

The framework for PISA 2006 does not only present a cutting-edge theoretical model of scientific literacy; it also suggests an innovative approach to measuring the science interest of students in an international large-scale assessment. The so-called embedded interest assessment uses the contextual and domain-related information of the cognitive science tasks as concrete and illustrative stimuli. In such an approach the students have a clear idea of what it means to be interested in science. Additionally, the approach allows the study of distinct features of a more or less general interest in science. An approach to getting additional information on students' interest in science by disentangling the PISA interest assessment will be presented in the following. The analyses focus on the connection between the contents of the cognitive test units and student interest.

In a first section of the paper a discussion of the role of interest in learning processes will substantiate the need for a closer look at science contents and contexts to which interests are related. The second part describes the methodological approach and deals with the different possibilities and problems the embedded interest assessment offers. Research questions are derived in the following section and afterwards, the methods section explains how interest is disaggregated and how subsequent group differences are calculated. Finally we present our findings and discuss them in light of further research questions.

\section{The Role of Interest}


please insert Figure 1 here: Framework for the PISA 2006 science assessment (derived from

OECD, 2006, p. 26)

From a literacy perspective, science education it is not confined to the development of scientific and science-related knowledge. The participation in a society that is highly influenced by science and technology also depends on motivational orientations, for example the willingness to further engage in scientific questions, topics and discussions. Science educators have always pointed out the importance of considering both cognitive and motivational aspects of scientific literacy (e.g. Millar, 2006). According to those ideas, the PISA science framework (Organisation for Economic Co-operation and Development [OECD], 2006) uses the concept of interest as one criterion to determine the extent to which young people have acquired the wider knowledge and skills in scientific literacy that they will need in adult life. Figure 1 illustrates that PISA aims to study scientific literacy comprehensively, taking a variety of aspects into account. Referring to the structure of the framework, several questions can be pursued, such as: What are appropriate contexts to test scientific literacy? What competencies, knowledge and attitudes can reasonably be expected from 15-year-old students?

PISA informs participating countries of the extent to which their students are prepared for the knowledge society at age 15. From the scientific literacy perspective described above, it is instructive to look at the relation between science performance and science interest at a country level. Are the countries which are successful with regard to science performance as good with regard to fostering student interest? First results from PISA 2006 (OECD, 2007b, p.54) suggest that this is not necessarily the case. Students in Finland as the best performing country in science in PISA 2006, display remarkably low interest in science, as do students in other high performing countries like the Netherlands, New Zealand, the UK and Australia. 
Only in a few countries, among them Germany, Japan and Austria, do we find an adequate level of interest in terms of the comprehensive definition of scientific literacy. Findings like this require a closer look at interest and its structure.

Interests play an important role in initiating, steering and retaining the engagement in specific domains and learning processes (Renninger, Hidi, \& Krapp, 1992; Schiefele, 2009). In educational research, interest has been conceptualised as a phenomenon that emerges from a person's interaction with an object or a certain content (Krapp, 2002). The personal side of this model has been well elaborated. Research has focused on a variety of the person aspects of the theory, e.g. attention (Ainley, Hidi, \& Berndorff, 2002; Hidi, Renninger, \& Krapp, 2004), goals (Harackiewicz, Barron, Tauer, \& Elliot, 2002; Pintrich \& Zusho, 2002; Sansone \& Smith, 2000) or levels of learning (Alexander \& Murphy, 1998; Hoffmann, 2002; Köller, Baumert, \& Schnabel, 2001). Interests, however, are not sufficiently described when looked at only from the personal side. The objects and domains of interest are sometimes described as opportunity structures for the development of interest. In most approaches, interest is regarded as being domain specific (Häussler \& Hoffmann, 1998; see also Krapp \& Prenzel, this volume). Nevertheless, a much smaller research body can be found on the object aspect (e.g. Prenzel, 1992; Renninger, Ewen, \& Lasher, 2002; Todt \& Schreiber, 1998) of interest. The topological perspective Häussler and colleagues adopted for the Leibniz-Institute for Science Education (IPN) study on physics interest focuses on the structure of the domain (Häussler, 1987; Hoffmann, Häussler, \& Lehrke, 1998). In their topological model of physics interest, they disentangle specific topics, contexts in which the topics are represented and activities in which the individual can engage. Students are systematically confronted with topics, application areas and activities related to physics.

This strategy was stimulating for the development of the embedded interest measures in PISA. While the IPN study used short texts to inform students about the actual topics, PISA 2006 refers to the situated assessment approach used in the cognitive tests. 


\section{Why Embedded Interest Measures?}

In science education, constructivist principles have been discussed for a long time (Duit \& Treagust, 2003; Fraser \& Tobin, 1998). Researchers emphasise the relevance of situations and contexts for understanding and for the construction of meaning, aspects that are also very relevant for valid assessments. PISA takes this into account, and subsequently designs its cognitive items in such a way that they provide a situation or context which puts students into the role of problem solvers in a specific situation. For its innovative interest measure, PISA takes advantage of this structure, even though it has some caveats that will be discussed below.

To construct the embedded interest measure, the structure of the cognitive test was used with its thematically differentiated units. A short description of the topic using a text, a picture and/or a graph, is followed by a number of test items that relate to the stimulus in the beginning. The stimulus introduces the topic and, at the same time, situates and contextualises the test items. In order to find out more about the role a certain context or content could play in the motivational processes, the interest measures are inserted at the end of a number of items of the cognitive test. Instead of giving rather unspecific indicators of being interested in domains like 'physics' or 'cell biology', students are asked to indicate their interest in specific topics. Interest is measured by asking whether or not a student would like to know more about what tooth decay bacteria look like under a microscope or to learn how the body recovers after stopping smoking. Students state their interest in a unipolar Likert-type rating scale.

With this methodological approach, used for the first time in 2006, PISA goes beyond the scope of traditional questionnaires. One major problem of conventional questionnairebased interest measures (and also the PISA interest questionnaire) is that in most cases, a relatively small number of interest items covers broad fields of contents and contexts. The resulting interest measure is rather global and does not give a precise picture of the huge and multifaceted field of science. Students have to give abstracted judgments (Schwarz, 1999), 
which are far more likely to be biased than concrete judgments. In order to give information about science interest, students need to summarise their interests in cell biology, astronomy, mechanics and many other scientific areas.

The PISA 2006 science test makes a first attempt to systematically differentiate a number of contexts (i.e. life situations that involve science and technology: health, natural resources, environment, hazards, but also the frontiers of science and technology) and a variety of knowledge areas (living systems, physical systems, technology systems or earth and space systems) which are relevant from a scientific literacy perspective (see Figure 1, OECD, 2006). Therefore, the item pool for the cognitive test offers a comprehensive constellation of science contexts and contents for measuring interests differentiated. As opposed to a traditional questionnaire, the embedded interest items offer a basis of rich information on concrete, situated and contextualised science topics.

In principle the interest structure could be described along the dimensions of the cognitive test. Several constraints, however, have to be taken into account. As a large scale study, PISA is carried out using a rotated booklet design that allows for a high number of test items in a limited span of time. Employing a rotated booklet design in an assessment means that not every student receives all test items. The rotated booklet design provides students with a balanced choice of items which represent only a small fraction of the entire number of items. In PISA 2006, $17 \%$ of the science testing time was devoted to attitudinal items; therefore, not all cognitive units were complemented by interest items. Interest items were designed 'for suitable units' (OECD, 2009b); that is, interest items were constructed only for a selection of units. In summary, this means that the data matrix for the embedded interest measures is incomplete and much sparser than the data matrix for the cognitive science assessment. With 52 items available from 13 units rotated over 13 booklets, our analysis models cannot comprise all facets of interest. It is, however, an attempt towards a more comprehensive picture. 
At first glance, the incomplete data structure is sufficient for analyses on an aggregated item level. A general indicator for interest in science can be successfully established on the data structure at hand. Using this aggregation, however, does not provide much extra information compared to the very global interest indicator based on the usual questionnaire approach in large-scale assessment. Thus, in order to disentangle dimensions of science interest in the PISA 2006 assessment, we refer to the interest item pool PISA produced.

From a theoretical point of view, a first step towards a differentiation of the global interest in science could take into account the context and the knowledge aspects from the PISA framework, i.e. the knowledge of science dimension. Figure 1 displays the structure of scientific literacy as defined in PISA. The framed aspects were the focus of our attention: the life situations that involve science and technology (contexts) and the systems within which central knowledge aspects are systematised. For the theoretical reasons mentioned above, assuming that science interest is organised along domains and within the structure of a domain, focused on certain contents, contexts and activities (see Häussler \& Hoffmann, 1998), we expected those aspects to be relevant in identifying dimensions of science interest.

In our study we adopted the argument that interest needs to be studied with regard to contents and contexts, in order to disentangle the object aspect of the person-object relation (Krapp, 2003). The PISA 2006 science assessment makes a first attempt to measure interests in the respective contexts.

The core of the present study is the multidimensional scaling of the embedded interest items. Instead of a global indicator for science interest, we investigate a more differentiated description of different facets of science interest.

\section{Analysing Different Groups with Regard to Dimensions of Science Interest}

Having found dimensions of science interest in the present data, we will pursue a number of questions that help to further clarify the picture by analysing group differences on 
various levels. Research on science interest has always found remarkable gender differences (Gardner, 1998; Hoffmann, 2002), and consequently we take a look at the distribution of the interest dimensions among boys and girls.

Findings from PISA analyses on science interests show that the connection between science performance and science interest is complex and difficult to discern (OECD, 2007a, b). The relationship between interest in science and achievement (on an individual as well as on a country level) has been the subject of research for more than 40 years (e.g. Baumert $\&$ Köller, 1998; Osborne, Simon, \& Collins, 2003), and thus we examine the connection between science performance and the dimensions of science interest. Earlier analyses show that high-performing students are overrepresented in the upper interest quartiles (Prenzel, Schütte, \& Walter, 2007), even though not all high-performing students are highly interested in science. Interest is an important predictor of high-performing students' choice of a sciencerelated career. In our analysis, we therefore focused on high-performing students (the upper performance quartile within a country), aiming at a more differentiated picture within this group.

On a country level science performance and science interest do not necessarily correspond in an educationally desired way. In some countries, low performance is associated with extremely high interest and vice versa. In order to reduce the complexity of this relationship, we decided to work with a selection of OECD countries. We chose a group of countries that is rather homogeneous with regard to performance and can be compared to one another in terms of the significance of the natural sciences and technology in society. The criterion for the choice of these countries was ranging above the OECD average on the combined science performance scale. Fourteen countries were included in these analyses.

Characteristics of the school systems and aspects of science teaching vary across the OECD countries (OECD, in prep.). Learning environments and their degree of stimulation with respect to the (natural) sciences are an important basis for the development of interests 
(Krapp \& Prenzel, this volume). Fostering scientific literacy means supporting the development of science competencies along with the development of science interest. On a country level, it is helpful to know the general level of science interest and tendencies in the distribution of dimensions of interest and learning preferences among 15 year olds. For example, this information is crucial for purposes like reducing and essentialising curricula.

Most of the countries selected for our analyses already suffer from or at least threaten to suffer from a lack of specialised workforce in the natural sciences (OECD, 2009a). Science interest is an important predictor of students' choice of a science-related career (OECD, 2006). Hence, from a motivational perspective, students with specialised interests are an interesting group to study. This group of students is characterised by a one-sided high interest in one dimension of interest with complementary low interest in the other dimension. Such an orientation might even approach a well-developed interest, which is a very sophisticated stage in the development of interest according to Hidi and Renninger (2006). It is interesting to pay special attention to students belonging to this group. As the selection of countries chosen for our analysis is strongly dependent on young scientists it is vital for those countries' schools to foster interest and engagement in science in order to convince as many highly interested and high-performing students as possible to make their vocational choice accordingly.

\section{Research Questions}

As mentioned above, the aim of this study is to explore the contribution of the embedded items for a deeper understanding of facets of science interest. Therefore, the first part of our analyses comprises the questions: Can interest in science be disaggregated with regard to specific components of scientific literacy? Do we find specific dimensions of science interest by which we can describe interest more precisely than in just one global science interest score? We expect that either the contexts PISA provides with the test units or the areas of scientific knowledge could be the basis of our disentangling analysis. 
Once we have found dimensions of science interest, we analyse group differences on an individual and a country level: We examine the distribution of interest dimensions with regard to gender and to performance groups (high-performing students).

Further, on a country level, we ask: Do we find specific preferences according to the dimensions of interest? Does the distribution of interests vary with respect to different highperforming OECD countries?

Eventually, we ask for specific profiles of interests in the high-performing countries. Do we find countries where the group of students with a one-sided high interest in one dimension with complementary low interest in the other dimension is larger than in others (and vice versa)?

\section{Methods}

\section{Sampling Procedures}

The following data analyses and results are based on the international dataset from PISA 2006: a representative sample of 15-year-old students assessed in all 30 participating OECD countries with the instruments of PISA 2006. The total number of students analysed is 251278 and the population covered by these students is 12933228 fifteen year olds from the OECD countries. For the purpose of analysing the multidimensional structure, a random sample of $10 \%$ of the cases of the complete dataset was used, and a sample size of 25476 OECD students was reached. In order to report further findings for OECD countries later in this paper, for each analysis the full sample was used. These analyses also employed the PISA survey weights.

\section{Item Pool}

Within the science assessment, interest items were constructed for 18 out of 37 science units. Seventeen percent of the testing time in science was devoted to the attitudinal component. The attitudinal assessment comprises items on 'interest in science', 'support for scientific enquiry' and the 'responsibility towards resources and environment' (OECD, 2006). 
Our study focuses on the interest aspect of the attitudinal component of scientific literacy, which was measured with 52 interest items embedded in 18 units.

\section{Test Format and Administration}

After having worked on the cognitive items, students were asked to rate their interest in the topics, objects and activities with which they had just been confronted. Three-item scales were constructed to measure interest within each of the units using four-point Likerttype scales from 'high interest' to 'no interest'. The generic item construction principle focuses the assessment of epistemic interest, e.g. knowing more, understanding better and learning more how/about. The questions were highlighted in grey to ensure that students regarded those questions as an extra part of the assessment which was not part of the cognitive science test. Students were told that there was no right or wrong solution to the questions. Figure 2 gives an example for the items.

please insert Figure 2 here: Example Items for interest in science. (Source: OECD, 2009b, p.36, for the cognitive unit, see p.104f.)

\section{Multidimensional Scaling of Interest in Science Items}

In order to disentangle science interest we considered the contexts and the knowledge of science categories as potential criteria. Following our theoretical assumptions from scientific literacy and, from an interest perspective, assuming that an object of interest is determined by contents (in the PISA framework the knowledge of science dimension), as well as by contexts, we analysed the interest items with regard to their science content. The contexts are operationalised as areas of application in the PISA 2006 framework (Figure 1), labelled as Frontiers of Science, Hazards, Environment, Health and Others. The contents distinguished in the PISA 2006 framework are living systems, technology systems, physical systems, earth and space systems (Figure 3). 
Data analyses were performed using multidimensional item response models specifying either context- or content-specific interests as dimensions measured by the respective interest items from the assessment. Note that science items measuring science performance were not used in these models. A multidimensional generalisation of the partial credit model (Masters, 1982) assuming equal slopes for all items was used to scale the item responses.

To find an adequate multidimensional model, we compared several multidimensional models, starting with one for the contexts, one for the contents and a unidimensional model as a control. The best fitting model was chosen using several selection criteria: (a) The number of interest items available for each context or content dimension must be sufficient. Given the rotated booklet design and the fact that only some science units were complemented with interest items, it is important to achieve a reasonably large proportion of students with observed interest items for each dimension. From a psychometrical perspective, we compared different multidimensional models with regard to several criteria: (b) the likelihood based fit index Bayesian information criterion BIC (Bozdogan, 1987), (c) the estimated latent person variances, and (d) reliabilities of the interest dimensions based on Expected A Posteriori estimates (EAP) were employed in order to test to what degree the dimensions discriminate interest between students. Additionally, (e) we compared average variances of the measurement errors as indicators for the precision of the interest estimates. All model results are reported in the logit metric defined by a multidimensional Rasch model with slopes fixed to either zero or one. The interest parameters refer to the mean item difficulty being zero within each scale. In order to investigate item fit, generalised partial credit models with slope parameters were employed, fixing a slope either to zero or estimating it. All multidimensional models were specified as (restricted) general diagnostic models (von Davier, 2007) and estimated via maximising the marginal likelihood using the egpcm software by von Davier (2009). 


\section{Results}

\section{Disaggregated Science Interest}

The first question asked for specific dimensions of science interest by which we can describe interest more precisely than through just one global science interest score. Pursuing this question required a reorganisation of the science units in order to identify meaningful dimensions of science interest. We considered the contexts and the knowledge of science categories as potential criteria (see Figure 1). In a first step, two 4-dimensional models were specified, one on contexts and the other on contents. Due to small item numbers, 'Health' and 'Environment' in the context model (M1, Table 1) were collapsed prior to the analysis. For the contexts model (M2, Table 1), three items that were not allocated to a context originally were considered close enough to be assigned to living systems. Thus, all model comparisons are based on all 52 interest items.

\# please insert Table 1 here: Multi-dimensional interest models, scale definitions and results

The dimensions of these models and the respective numbers of items are reported in Table 1, as well as scale means, variances, reliabilities, average error variances of the EAP estimates and correlation matrices. Note that all results in this section were computed on a $10 \%$ random sample of the full dataset of $\mathrm{N}=25476$ students without employing survey weights. The table further displays results from two more models derived from the contents model (M2): To construct alternative models with more items in their dimensions, we reorganised the dimensions of knowledge of science with regard to their content. To eliminate the dimensions consisting of only five items, an alternative model with three content dimensions (M3) is proposed. The former living systems dimension now includes three items on earth and space (from the unit 'dinosaurs') and the former physical systems dimension now includes another two items (from the unit 'moon'). The earth and space units were 
redistributed: the unit on dinosaurs was allocated to the living systems category, the unit on the moon was assigned to the physical/technology systems category as this is more focused on physical than on living system aspects.

Another model (M4) further collapses physical systems and technology systems into one dimension. The new categories comprise living systems and physical/technology systems in a broader sense and are illustrated in Figure 3. The physical and the technological systems categories are taken together as one dimension. The results of the estimation of these two further models are also reported in Table 1. As a control model, Table 1 also displays the results of a unidimensional model (M5).

Table 2 presents likelihood results which allow for comparing the goodness of fit from these five models. With respect to the BIC, the model on four content dimensions (M2) fits the data best, the model on four context dimensions fits the data second best, model M3 on three contents fits the data third best, followed by model 4 on two content dimensions. As expected, the unidimensional model has the worst fit among all five models. Since models M1, M2 and M3 are rather close in their BIC index, each of these models could potentially be used to describe the structure of interest in science.

please insert table 2 here: Multi-dimensional interest models, goodness of fit

M2 shows the highest standard deviations and reliabilities among all five models (see Table 1), indicating that these four dimensions best discriminate students' interests in science. However, the standard deviations and reliabilities of model M1 are similar. The three content dimensions of model M3 are virtually the same as the respective content dimensions in model M2. The standard deviations and reliabilities from the two-dimensional content model are close to the respective content dimensions of M3 and M2, quite close for living systems and somewhat smaller for the collapsed dimension physical/technology systems. The 
unidimensional model shows the smallest standard deviation and a rather high reliability. Note that the reliabilities given are derived from EAP estimates, and thus are based on the items of the respective dimensions and on the covariance among all dimensions of a model. The average error variance (of the EAPs) of each dimension provides a closer look into the measurement precision of the estimates. This error variance obviously correlates with the number of items: M5 shows the smallest error, while the dimension defined on five items for earth and space systems in model M2 shows the greatest error. In terms of measurement error the unidimensional model and model M4 are considered best; the other three models are less precise in measuring their dimensions.

Another indicator for the appropriateness of a model might be the fit of its items. Table 3 presents the number of items from each model that do not fit well according to the root mean square error of approximation (RMSEA) between the expected and observed item characteristic curves. A value greater than 0.05 is regarded as an indication of the misfit of a particular item. The numbers of non-fitting items range from 9 items in M4 to 17 items from the total of 52 items in M1.

please insert table 3 here: Multi-dimensional interest models, number of non fitting items

In order to check whether these misfits might be explained by a bad fit of the items into the assumed multidimensional structures expressed by the models, we reestimated the five models, specifying different slopes for each item. Thus, the reestimated models are multidimensional generalisations of a generalised partial credit model (GPCM), with two parameters for each item (labelled 2PL). The numbers of non-fitting items are given in Table 3; Table 4 shows the likelihood results for the reestimated 'slopes'-models.

please insert table 4 here: Multi-dimensional interest models with slopes, goodness of fit 
With respect to the BIC, the reestimated slopes models show a better fit than the respective multidimensional Rasch models, as expected (Table 4). With estimated slopes, the three contents model M3 seems to be the best fitting model. Allowing each item to fit into the multidimensional structure to its own degree obviously reduces the number of dimensions needed to explain the observed responses. The descriptive statistics, variances, correlations and reliabilities of these models are quite similar to the values of the corresponding multidimensional Rasch models (see Table 1) and are not reported here.

The number of non-fitting items from the slopes models range from zero to nine items (see Table 3). For the unidimensional model M5 and the two contents model M4, all item misfits seem to be due to an unfitting (too restrictive) multidimensional structure, since these items fit when estimating their slopes. For the other three models, the results are somewhat more complex. Assuming higher dimensional models fitting the data (M1, M2 and M3), the number of non-fitting items should become smaller. However, with higher dimensional models, the discriminations of the dimensions increase as well and the item fit statistic shows a higher sensibility to item misfit. By allowing slopes for these models, however, the number of non-fitting items is reduced, even if some items with bad fit remain.

An inspection of the slope parameters reveals which items do not fit well into the dimensional structure. By definition, in our slopes models, the mean of the slopes is set to one. If a generalised Rasch model holds as well, most slope parameters will be close to one. With the unidimensional slopes model M5-2PL, most items show slopes around 1, ranging from about 0.8 to 1.2; only some single items and the items from units S519 'airbags' and S527 'extinction of the dinosaurs' show lower slopes, down to 0.6. The items of unit S519 fit well within the three- and four-dimensional slope models M3-2PL and M2-2PL. The items in unit S527 only show slopes sufficiently close to one in the four contents model M2-2PL. 
Given the results presented above, choosing a multidimensional model according to different criteria will result in different choices. Discriminative power (i.e. standard deviation and reliabilities) would allow the use of both four-dimensional models, supported by the global model fit. With a high priority for measurement precision and for not having too few items in a dimension, one could decide to base further reporting on the three content model M3. If the numbers of items for each dimension should also be fairly well balanced, the two content models M4 would be optimal.

\section{Results for the Dimensions of Interest in the OECD Countries}

In the remainder of this paper, we present interest results for OECD countries. Even though other models are more sophisticated and fine-grained, the distinction between living systems on the one hand and physical and technological systems on the other resembles the content structure of science as a domain very well, as seen from a student perspective. The distinction provides the strongest contrast, both psychologically and regarding the content aspect of interest. Vocational choices are made along these categories, too, as they reveal a typical area of tension. We therefore further analyse student interests with regard to the two content subscales of science interest of model M4, physical/technology systems, based on 22 items and living systems, based on 30 items. This model's dimensions are illustrated in Figure 3.

please insert Figure 3 here: The Reorganisation of the Knowledge of Science-Categories

In a first step, the two dimensions of interest were analysed for the OECD countries' sample. The results are presented on a logit scale defined by the item response model; all results reported below were computed on the complete country samples using the PISA survey weights. The mean (M) for the living systems dimension is $M=0.34$, with Standard Deviation $\mathrm{SD}=1.45$ and Standard Error S.E.=0.013. For the physical/technology systems, we 
find $\mathrm{M}=0.33$ with $\mathrm{SD}=1.47$ and S.E. $=0.012$. The latent correlation between the two dimensions is $r_{\text {living systems, physical/technology systems }}=0.80$. The latent correlation shows a remarkable overlap between the two dimensions which, however, tends to be somewhat lower than the correlation between the performance in the different PISA domains (OECD, 2009b, p. 215). This finding once again supports the result that the two dimensions of science interest can be seen as two distinct categories.

We analysed gender differences at a country level, i.e. for the entire sample of students in the OECD countries. Figure 4 displays the results: The means for the interest dimensions with regard to gender range from 0.21 to 0.45 . Girls show a more pronounced interest in topics in the field of living systems compared with the topics of Physical/Technology Systems, and for boys it is the opposite, even though the differences between the dimensions are slightly smaller for boys than for girls. For the living systems dimension, we find a small difference between girls and boys $\left(M_{\text {girls }}=0.33\right.$, S.E. $=0.017$ vs. $M_{\text {boys }}=0.35$, S.E. $\left.=0.014\right)$, while it is larger (and statistically significant) for the Physical/Technology Systems dimension $\left(\mathrm{M}_{\text {girls }}=0.21\right.$, S.E. $=0.016$ vs. $\mathrm{M}_{\text {boys }}=0.45$, S.E. $\left.=0.014\right)$

please insert Figure 4 here: Gender differences for two dimensions of interest in the OECD sample

Using a subsample of students consisting of the students in the highest performance quartile, we explored the question: Do high-performing students differ in the dimensions of interest from the complete sample of students in the OECD countries? Figure 5 presents the results, analysed separately for males and females.

\# please insert Figure 5 here: Differences for high performing students (upper quartile) for the two dimensions of interest versus the other students in the OECD sample 
Compared to the other students in the OECD sample, the students in the subsample of highperforming students are significantly more interested in both dimensions of interest. This applies for boys $(53.6 \%)$ as well as for girls $(46.4 \%)$. The gender differences among the high performers go in the same direction as for the whole sample. The picture of gender differences for the high-performing students resembles the situation of the entire OECD sample, only on a higher level of interest. Boys and girls in the highest-performing quartile of the sample are equally interested in living systems $\left(\mathrm{M}_{\text {girls }}=0.56, \mathrm{~S} . \mathrm{E} .=0.022 \mathrm{vs.} \mathrm{M}_{\text {boys }}=0.55\right.$, S.E.=0.022). For Physical/Technology Systems there is a clear and statistically significant difference in favour of the boys: $M_{\text {girls }}=0.30$, S.E. $=0.022$ vs. $M_{\text {boys }}=0.56$, S.E. $=0.024$. In fact, the level of boys' interest in Physical/Technology Systems for the whole sample $(\mathrm{M}=0.41$, S.E. $=0.016)$ is considerably higher than the high-performing girls' interest in this dimension. The already small interest difference for males for the two dimensions dissolves completely in the high-performing subpopulation: Boys in the highest quartile are equally interested in Living and Physical/Technology Systems.

In the next step we analysed whether or not the distribution of interests varies for the OECD countries ranging significantly above the OECD mean in science performance. For this analysis we compared 14 high performing OECD countries with the OECD average. On first glance, Figure 6 displays remarkable differences in the interest structure of highperforming countries.

please insert Figure 6 here: Interest in living vs. physical/technology systems: all students

The scores for both interest dimensions in countries like Japan $\left(\mathrm{M}_{\text {living }}=0.41\right.$, S.E. $=0.041, \mathrm{M}_{\text {phys./tech. }}=0.44$, S.E. $\left.=0.043\right)$, Austria $\left(\mathrm{M}_{\text {living }}=0.31\right.$, S.E. $=0.051, \mathrm{M}_{\text {phys./tech. }}=$ 0.37, S.E. $=0.046)$ and Germany $\left(\mathrm{M}_{\text {living }}=0.39\right.$, S.E. $=0.038 \mathrm{M}_{\text {phys./tech. }}=0.44$, S.E. $\left.=0.043\right)$ are 
rather high, which means that they are similar to the OECD average. The fact that on the OECD level the average interest is approximately similar to the countries with highly interested students is due to the selection of (high-performing) countries: It is a common finding in PISA that low-performing countries show considerable interest compared to high performers. In other, likewise high-performing countries like the Netherlands $\left(\mathrm{M}_{\text {living }}=-0.38\right.$, S.E. $=0.045 \mathrm{M}_{\text {phys./tech. }}=-0.34$, S.E. $\left.=0.043\right)$, Finland $\left(\mathrm{M}_{\text {living }}=-0.43\right.$, S.E. $=0.045, \mathrm{M}_{\text {phys./tech. }}=$ -0.34$, S.E. $=0.044)$ or New Zealand $\left(\mathrm{M}_{\text {living }}=-0.18\right.$, S.E. $=0.042, \mathrm{M}_{\text {phys./tech. }}=-0.24$, S.E. $=0.042$ ), the interest scores are quite low for both dimensions of interest, compared to the OECD average $\left(\mathrm{M}_{\text {living }}=0.34\right.$, S.E. $=0.013, \mathrm{M}_{\text {phys./tech. }}=0.33$, S.E.=0.012). Regarding the dimensions of interest we also find considerable differences within the countries: As opposed to the OECD means which indicates slightly higher interest for the living systems dimension than for the physical/technology systems dimension, we find an interest preference for physical/technology systems in a number of high-performing countries: Ireland, Austria, Germany, the Netherlands, Japan and Finland. It needs to be mentioned that in some countries this difference is on a rather high-interest level, in others on a low level, each compared to the OECD average. In order to have a realistic impression of the differences we translated the displayed scores back to the original values on the interest scale. The four-point Likert scale comprises the categories $0=$ no interest, $1=$ low interest, $2=$ medium interest and $3=$ high interest. On average for the entire OECD sample, the mean for the two interest dimensions is $\mathrm{M}_{\text {rawscore-living }}=1.66$ and $\mathrm{M}_{\text {rawscore-phys/tech. }}=1.63$. For the Netherlands, for example, one of the countries with the lowest interests, the means are $\mathrm{M}_{\text {living }}=1.32$ and $\mathrm{M}_{\text {phys/tech. }}=1.32$.

Finally we asked for specific profiles of interest dimensions in the high performing countries. We asked whether, within a country, we could identify groups of students scoring high on one dimension of interest while the other dimension is of minor interest for them. In order to answer this question we calculated interest ratios for the high-performing countries. The analysis was carried out by applying a median split of interest scores in both dimensions 
within the data of the OECD countries differentiating higher versus lower interest in each of the interest dimensions. The OECD acts as the reference group for this analysis. We then analysed profiles of students indicating higher or lower interest in living systems and physical/technology systems. In the OECD, $9 \%$ of the students were found to indicate a profiled interest either way rather than indicating a higher or lower interest in both dimensions.

please insert Table 5 here: Interest Profiles for the high performing OECD-countries

Table 5 displays the percentages of students with (nonprofiled and) profiled interests. On the OECD level a total of $82 \%$ of the students are 'nonprofiled', i.e. they either score high or low in both dimensions of interest (Column 2 and 5). The interesting groups are $9 \%$ of the students who are either not interested in living systems while they are at the same time highly interested in physical/technology systems (Column 3), and another $9 \%$ of the students who are highly interested in living systems and score low in the physical/technology dimension (Column 4). If we look at Finland, the highest performing OECD country in science, we find that $63.7 \%$ of the students are not interested in either dimension of science interest. Column 3 describes the percentages of students with profiled interests: In Finland, 9.9\% of the students are strongly interested in physical/technology systems and not interested in living systems, slightly more than on the OECD level. The interests for the group of students in Column 4 are profiled vice versa. Those students are highly interested in living systems and hardly interested in physical/technology systems. For Finland as an example country, such students represent $6.7 \%$ of the sample, less than for the OECD sample. Column 5 displays the students who score high in both dimensions of science interest, which applies for $19.8 \%$ of the Finnish students. The last column gives a ratio that allows an estimation in comparison to the OECD mean: A ratio below 1 implies that the group of students who are not interested in living 
systems while at the same time they are interested in physical/technology systems is larger than the group where it is vice versa. Finland is an example country that shows that, compared to the OECD average, there is a larger group with one-sided interest in Physical/Technology Systems and a smaller group of students whose interest profile is the other way around. This also applies for Japan, the Netherlands, Germany, the UK, Austria and Ireland. Canada, New Zealand, Australia, Korea, the Czech Republic, Switzerland and Belgium are the highperforming OECD countries where it is the other way around: In those countries the group of students which is unidirectionally interested in living systems is larger than in the OECD average.

\section{Discussion and Conclusion}

This study aimed at exploring new methodological approaches to optimise the analyses of the insights from PISA data, i.e. the embedded science interest assessment. Our paper provides an approach to generate additional information on student interest in science by disentangling dimensions of the PISA interest assessment.

The empirical results showed that all multidimensional models have the potential to discriminate students along all dimensions of science interest analysed here. With regard to global model fit, the four-dimensional models are well suited to describe the interest structure; however, the three- and two-dimensional content models are applicable as well. The fit of single items was analysed by an item fit statistic and by estimating slopes in alternative slope models. An inspection of the estimated slopes revealed that with a few exceptions, all items fit into the multidimensional structure of the four-dimensional content model. Two units were found to fit within the four-dimensional content model M2 but not within any of the other models.

In summary, the multidimensional analyses seem to be best suited to reflecting the dimensionality of the interest items model M2. Thus, the assessment of a multidimensional structure of interest aimed at with the embedded items was successful. However, defining a 
dimension on only five items does not warrant stable results from further analyses. Therefore, we constructed alternative models on three and two dimensions. With further analyzing M3 instead of M2 or M4 instead of M3, reporting may lose a bit of the potential to obtain differential insights into science interest structure but gains stability in the results. With regard to the numbers of items in each dimension, it might be indicated to report interest along the content dimensions based on the three- or two-dimensional models M3 or M4.

From a methodological perspective, however, some remaining challenges should be pointed out. The main disadvantage of implementing the innovative approach in PISA 2006 lies in the small number of interest items distributed over a complex rotated booklet design: This does not necessarily support a fine-grained analysis of interest dimensions and their interrelations. In order to examine interest dimension structures more comprehensively, a higher number of embedded items in the respective dimensions would be helpful. Ideally, if more testing time could have been allocated for the embedded attitudinal items, a minimum of 3 units comprising 9 interest items for each designated dimension within the 29 newly constructed science units in PISA 2006 would have been appropriate. Our analyses contribute to a better estimation of the required number of items. Even if the test construction is a very complicated procedure and the required number of items is high, we find the results at hand already quite instructive and we conclude that eventually, it would be very interesting to pursue this approach. If it is too complicated to do so in a large scale format that employs a rotated booklet design, it could instead be carried out in other studies, even in other-large scale studies like in standard-based assessments where all students work on all test items.

For further reporting in this paper we choose model M4 differentiating science interest along the prominent distinction in life sciences, living systems in terms of PISA and rather hard, physical and technological sciences, called physical systems and technology systems in PISA. According to these two categories, we found gender differences that support findings from a number of studies and indicate that males and females are about equally interested in 
living systems, while males' interest in physical/technology systems is higher than that of females. This also applies for students in the upper quartile of the performance scale. The interest level in the group of high-performing students is higher than in the entire sample. Boys and girls show considerable interest on a comparable level. High-performing girls are less interested in Physical/Technology Systems than the boys of the same group.

From a teaching perspective it is important to understand the students' motivational situation and to know their learning preferences in order to adaptively foster interests and to design instruction in a way that meets specific learning preferences (Darling-Hammond \& Bransford, 2005). This is supported by the results presented. Knowing the preferences and special interests of students, boys as well as girls, can help to improve instruction in the natural sciences.

Studying the high-performing countries resulted in interesting findings: Firstly, for high performing countries in the OECD sample we find considerable differences in the level of interest. Figure 6 shows that high performance in a country is not necessarily complemented with high interest levels. The ideal stated in the definition of scientific literacy in PISA is not reached in a number of countries. Taking a closer look at the dimensions of interest reveals further considerable differences. In some countries students prefer living systems, while in other countries physical/technology systems are of higher interest to students.

So-called profiled interests were also studied: For the high-performing countries, the group of students with high interest in one dimension complemented with a low level of interest in the other dimension and vice versa was studied. We found countries with profiles in favour of the living systems dimension with a higher percentage of students in this group and countries where the profiled group with a preference for the Physical/Technology Systems is larger, as shown in the ratio built in comparison to the reference ratio of 1 on the OECD level. 
From an educational systems perspective, these findings on the country level are very instructive with regard to fostering interests. For high-performing countries it is interesting to know how successful they are in fostering interest in science and at the same time enabling the development of high performance in science.

Students with specialised interests are also very interesting from a teaching perspective. They indicate high interest in one dimension while simultaneously disregarding the other dimension. In societies which are in need of specialised scientists, these groups can be very important, as interests play an important role in vocational choices. Another perspective is the educational goal of supporting the development of competence along with the development of interests. Fostering interests could be a differentiated and systematic process, starting from an area of interest and transferring to aspects in the wider context of one topic. Hence, the interest profiles can be helpful in finding out about learning preferences in relation to the need to foster interests.

The present findings leave some questions unanswered; therefore, analyses will be conducted in order to further describe students' interest in more detail, in terms of their connection to students' views on a science-related career or background variables like socioeconomic factors or other parental variables. 


\section{References}

Ainley, M., Hidi, S., \& Berndorff, D. (2002). Interest, learning, and the psychological processes that mediate their relationship. Journal of Educational Psychology, 94(3), 545-561.

Alexander, P. A., \& Murphy, P. K. (1998). Profiling the differences in students' knowledge, interest, and strategic processing. Journal of Educational Psychology, 90, 435-447.

Baumert, J., \& Köller, O. (1998). Interest research in secondary level I: An overview. In L. Hoffmann, A. Krapp, K. A. Renninger, \& J. Baumert (Eds.), Interest and Learning (pp. 241-256). Kiel, Germany: IPN.

Bozdogan, H. (1987): Model selection and Akaikes information criterion (AIC): The general theory and its analytical extensions. Psychometrika, 52(3), 345-370.

Darling-Hammond, L., \& Bransford, J. (Eds.). (2005). Preparing teachers for a changing world: What teachers should learn and be able to do. San Francisco: Jossey-Bass.

Duit, R., \& Treagust, D. (2003). Conceptual change--A powerful framework for improving science teaching and learning. International Journal of Science Education 25, 671688.

Fraser, B., \& Tobin, K. (Eds.). (1998). International handbook of science education. Dordrecht, The Netherlands: Kluwer Academic Publishers.

Gardner, P. L. (1998). The development of males' and females' interests in science and technology. In L. Hoffmann, A. Krapp, K. A. Renninger, \& J. Baumert (Eds.), Interest and Learning (pp. 41-57). Kiel, Germany: IPN.

Harackiewicz, J.M. Barron, K.E., Tauer, J.M., \& Elliot, A.J. (2002). Predicting success in college: A longitudinal study of achievement--Goals and ability measures as predictors of interest and performance from freshman year through graduation. Journal of Educational Psychology, 94(3), 562-575. 
Häussler, P. (1987). Measuring students' interest in physics--Design and results of a crosssectional study in the Federal Republic of Germany. International Journal of Science Education, 9, 79-92.

Häussler, P., \& Hoffmann, L. (1998). Qualitative differences in students' interest in physics and the dependence on gender and age. In L. Hoffmann, A. Krapp, K. A. Renninger, \& J. Baumert (Eds.), Interest and Learning (pp. 280-289). Kiel, Germany: IPN.

Hidi, S., \& Renninger, K. A. (2006). The four-phase model of interest development. Educational Psychologist, 41(2), 111-127.

Hidi, S., Renninger, K. A., \& Krapp, A. (2004). Interest, a motivational variable that combines affective and cognitive functioning. In D. Y. Dai \& R. J. Sternberg (Eds.), Motivation, emotion, and cognition (pp. 98-118). Hillsdale, NJ: Lawrence Erlbaum.

Hoffmann, L. (2002). Promoting girls' interest and achievement in physics classes for beginners. Learning and Instruction, 12(4), 447-466.

Hoffmann, L., Häussler, P., \& Lehrke, M. (Eds.). (1998). Die IPN-Interessenstudie Physik. Kiel, Germany: IPN.

Köller, O., Baumert, J., \& Schnabel, K. (2001). Does interest matter? The relationship between academic interest and achievement in mathematics. Journal for Research in Mathematics Education, 32, 448-470.

Krapp, A. (2002). Structural and dynamic aspects of interest development: Theoretical considerations from an ontogenetic perspective. Learning and Instruction, 12(4), 383-409.

Krapp, A. (2003). Interest and human development: An educational-psychological perspective. British Journal of Educational Psychology, Monograph Series II (2), 57-84 (Development and Motivation: Joint Perspective).

Marshall, S., Scheppler, J., \& Palmisano, M. (Eds.) (2002). Science literacy for the 21st century. Amherst, MA: Prometheus. 
Masters, G. N. (1982). A Rasch model for partial credit scoring. Psychometrika, 47(2), 149174.

Millar, R. (2006). Twenty first century science: Insights from the design and implementation of a scientific literacy approach in school science. International Journal of Science Education, 28(13), 1499-1521.

Organisation for Economic Co-operation and Development. (2006). PISA assessing scientific, reading and mathematical literacy: A framework for PISA 2006. Paris: OECD.

Organisation for Economic Co-operation and Development. (2007a). PISA 2006: Science competencies for tomorrow's world--Volume I: Analysis. Paris: OECD.

Organisation for Economic Co-operation and Development. (2007b). PISA 2006: Science competencies for tomorrow's world--Volume II: Data. Paris: OECD.

Organisation for Economic Co-operation and Development. (2009a). Education at a glance 2009: OECD Indicators. Paris: OECD.

Organisation for Economic Co-operation and Development. (2009b). PISA 2006 technical report. Paris: OECD.

Organisation for Economic Co-operation and Development. (in prep.). PISA 2006. Thematic report: Teaching and learning of science. Paris: OECD.

Osborne, J., Simon, S., \& Collins, S. (2003). Attitudes towards science: A review of the literature and its implications. International Journal of Science Education, 25(9), 1049-1079.

Pintrich, P. R., \& Zusho, A. (2002). The development of academic self-regulation: The role of cognitive and motivational factors. In A. Wigfield \& J. S: Eccles (Eds.), Development of achievement motivation (pp. 249-284). San Diego, CA: Academic Press. 
Prenzel, M. (1992). The selective persistence of interest. In K. A. Renninger, S. Hidi, \& A. Krapp (Eds.), The role of interest in learning and development (pp. 71-98). Hillsdale, NJ: Erlbaum.

Prenzel, M., Schütte, K., \& Walter, O. (2007) Interesse an den Naturwissenschaften. In M. Prenzel, C. Artelt, J. Baumert, W. Blum, M. Hammann, E. Klieme, \& R. Pekrun (Eds.), PISA 2006. Die Ergebnisse der dritten internationalen Vergleichsstudie (pp. 107-124). Münster, Germany: Waxmann.

Renninger, K. A., Ewen, L., \& Lasher, A. K. (2002). Individual interest as context in expository text and mathematical word problems. Learning and Instruction, 12(4), 467-491.

Renninger, K. A., Hidi, S., \& Krapp, A. (1992). The role of interest in learning and development. Hillsdale, NJ: Lawrence Erlbaum.

Sansone, C., \& Smith, J. L. (2000). The 'how' of goal pursuit: Interest and self-regulation. Psychological Inquiry, 11(4), 306-309.

Schiefele, U. (2009) Situational and Individual Interest. In K. A. Wentzel \& A. Wigfield (Eds.), Handbook of motivation at school (pp. 197-222). New York: Routledge.

Schwarz, N. (1999). Self-reports: How the questions shape the answers. American Psychologist, 54, 93-105.

Todt, E., \& Schreiber, S. (1998). Development of interests. In L. Hoffmann, A. Krapp, K. A. Renninger, \& J. Baumert (Eds.), Interest and Learning (pp. 25-40). Kiel, Germany: IPN.

von Davier, M. (2007). Hierarchical general diagnostic models (ETS Research Rep. No. RR07-19). Princeton, NJ: ETS.

von Davier, M. (2009). GuiDM general diagnostic model software (version 31.08.2009). Princeton, NJ: ETS. 


\begin{tabular}{|c|}
\hline $\begin{array}{l}\text { Context } \\
\text { Life situations that involve } \\
\text { science and technology }\end{array}$ \\
\hline $\begin{array}{l}\text { - Health } \\
\text { - Natural resources } \\
\text { - Environment } \\
\text { - Hazards } \\
\text { - Frontiers of science } \\
\text { and technology }\end{array}$ \\
\hline
\end{tabular}

How they do so is influenced by:

\section{Knowledge}

- About the natural world (knowledge of science)

- Living Systems

- Physical Systems

- Technology Systems

- Earth and Space

Systems

- About science itself (knowledge about science)

\section{Competencies}

- Identify scientific issues

- Explain phenomena scientifically

- Use scientific evidence

\section{Attitudes}

Response to science issues

- Interest

- Support for

scientific enquiry

- Responsibility 


\section{ACID RAIN}

How much interest do you have in the following information?

Tick only one box in each row.

$\begin{array}{cccc}\text { High } & \text { Medium } & \text { Low } & \text { No } \\ \text { Interest } & \text { Interest } & \text { Interest } & \text { Interest }\end{array}$

a) Knowing which human activities contribute most to acid rain
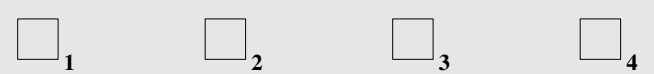

b) Learning about technologies that minimise the emission of gases that cause acid rain
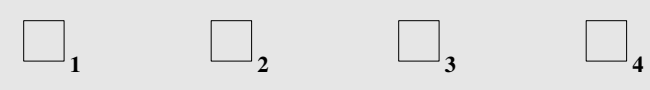

c) Understanding the methods used to repair buildings damaged by acid rain
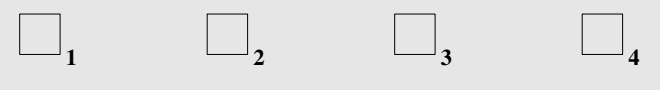
Categories of

knowledge of science $\quad \mathrm{N}$ of ltems

Living Systems

Physical Systems

24

Technology Systems

11

Earth and Space

9

Systems

5

Not assigned to a

category

\section{Interest Contents}

Living Systems

Physical/Technology

Systems
N of Items 30 22 


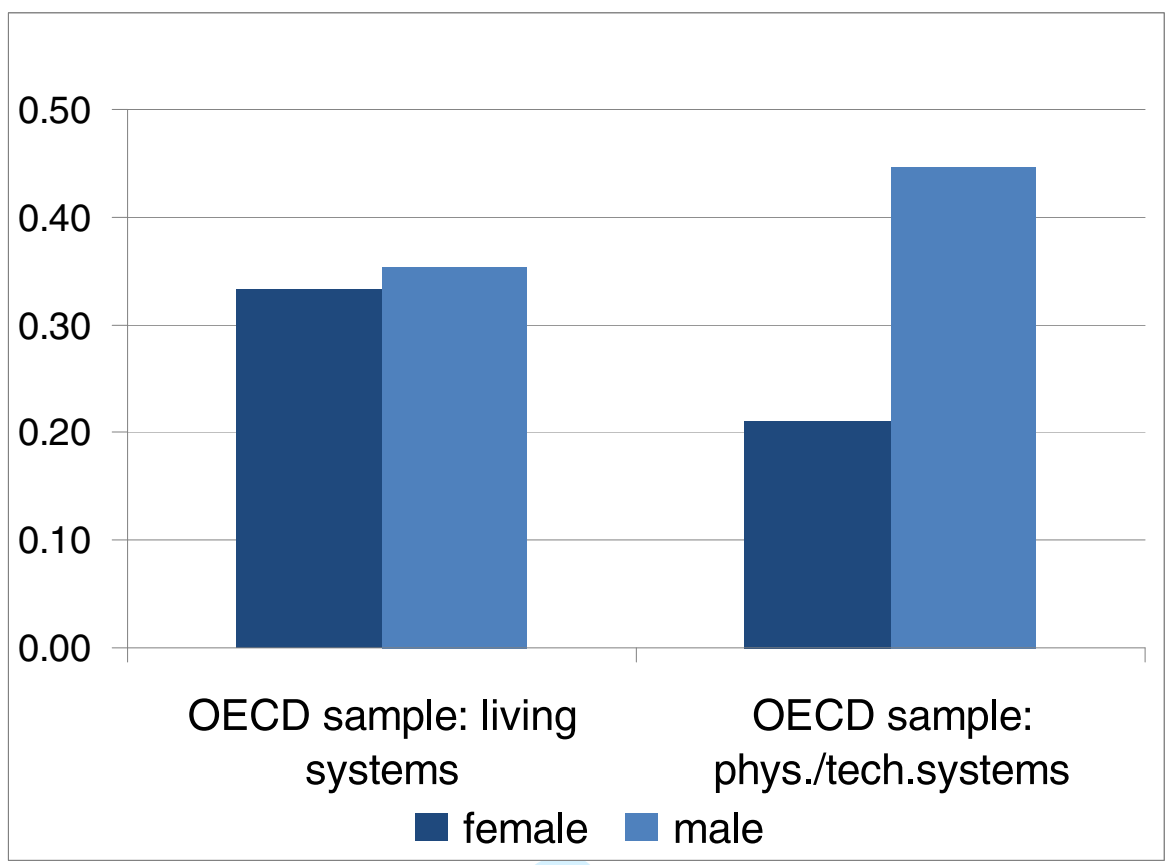




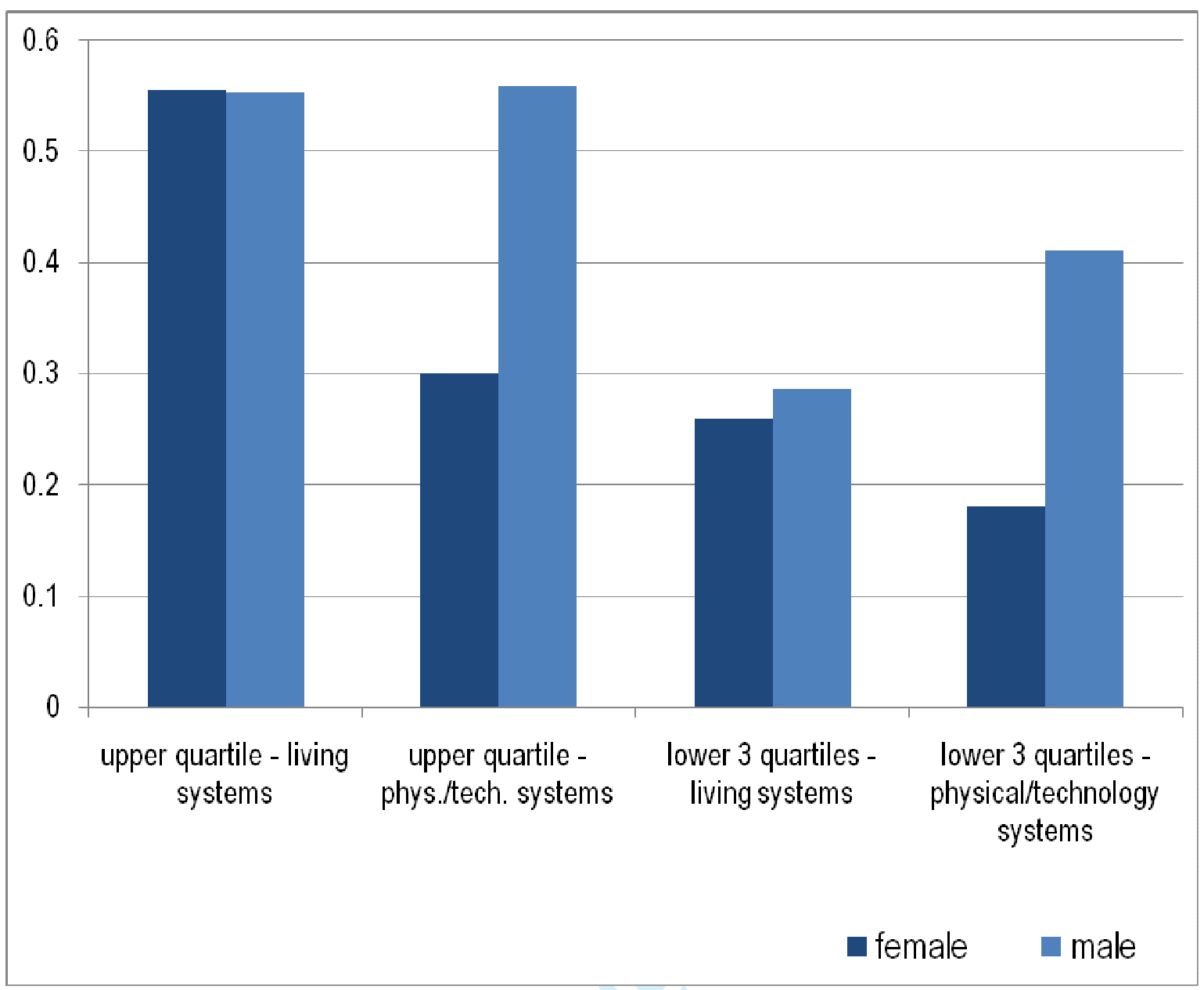




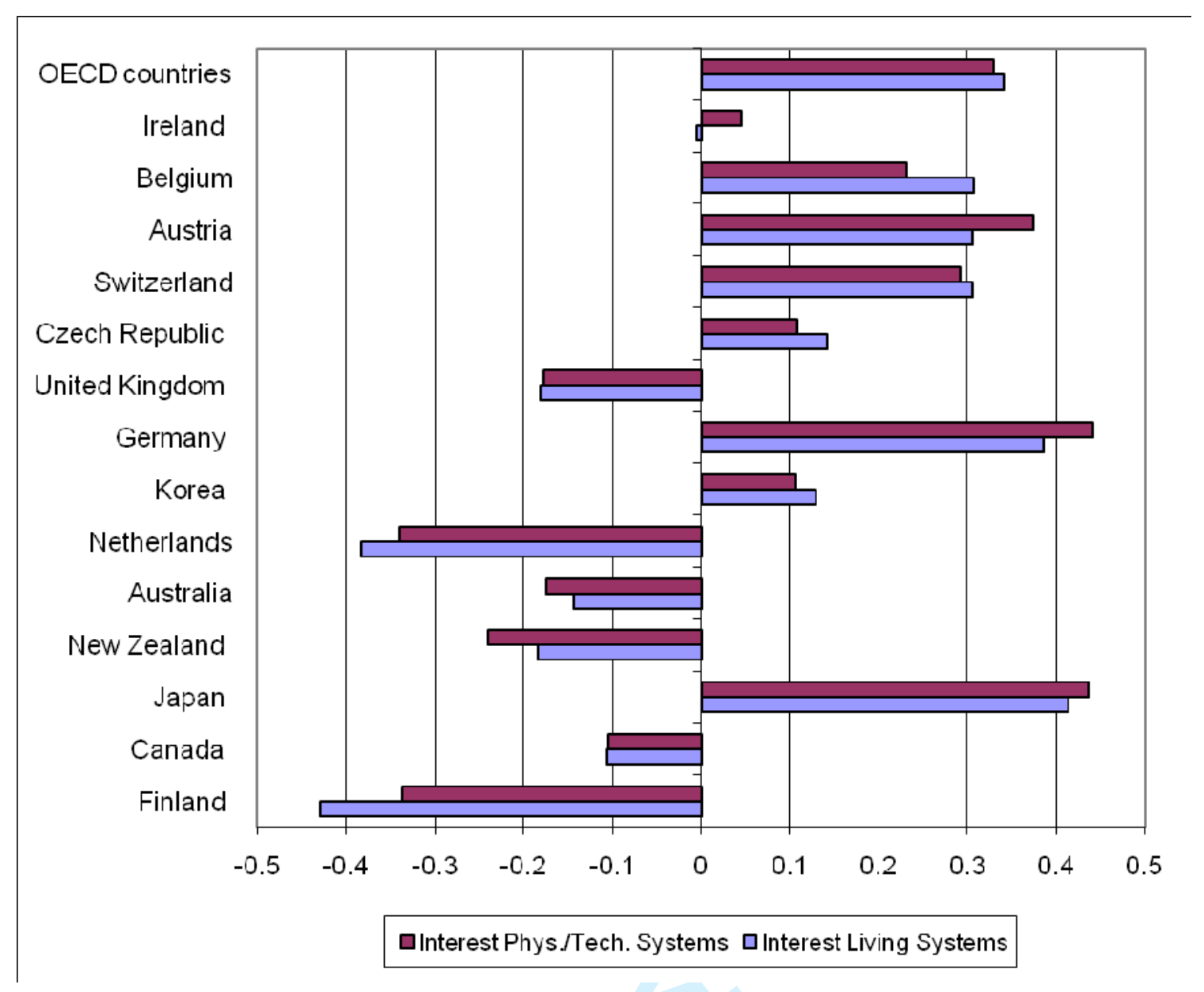

URL: http://mc.manuscriptcentral.com/tsed Email: editor_ijse@hotmail.co.uk 


\begin{tabular}{|c|c|c|c|c|c|c|c|c|c|c|}
\hline \multirow{2}{*}{$\begin{array}{l}\text { Model } \\
\text { M1 "contexts 4D" }\end{array}$} & \multirow[t]{2}{*}{ Scale } & \multirow[t]{2}{*}{$\begin{array}{l}\text { Number of } \\
\text { items }\end{array}$} & \multirow[t]{2}{*}{ Mean } & \multirow[t]{2}{*}{$\begin{array}{l}\text { Standard } \\
\text { Deviation }\end{array}$} & \multirow[t]{2}{*}{ Reliability } & \multirow[t]{2}{*}{$\begin{array}{l}\text { Error } \\
\text { Variance }\end{array}$} & \multicolumn{4}{|c|}{ Correlation Matrix } \\
\hline & & & & & & & health_env & frontiers & hazards & resources \\
\hline & health_env & 12 & 0.50 & 1,70 & 0.72 & 0.52 & 1 & & & \\
\hline & frontiers & 17 & 0.29 & 1,52 & 0.66 & 0.42 & 0.70 & 1 & & \\
\hline & hazards & 12 & 0.60 & 1,65 & 0.72 & 0.59 & 0.64 & 0.68 & 1 & \\
\hline & resources & 11 & 0.29 & 1,71 & 0.73 & 0.60 & 0.74 & 0.73 & 0.65 & 1 \\
\hline \multirow[t]{5}{*}{ M2 "contents 4D" } & & & & & & & earth \& space & living & physical & technology \\
\hline & earth \& space & 5 & 0.85 & 1,73 & 0.70 & 0.72 & 1 & & & \\
\hline & living & 27 & 0.36 & 1,56 & 0.78 & 0.34 & 0.61 & 1 & & \\
\hline & physical & 11 & 0.61 & 1,65 & 0.64 & 0.62 & 0.57 & 0.65 & 1 & \\
\hline & technology & 9 & 0.13 & 1,79 & 0.78 & 0.64 & 0.55 & 0.72 & 0.65 & 1 \\
\hline \multirow[t]{4}{*}{ M3 "contents 3D" } & & & & & & & living & physical & technology & \\
\hline & living & 30 & 0.40 & 1,51 & 0.79 & 0.31 & 1 & & & \\
\hline & physical & 13 & 0.61 & 1,61 & 0.62 & 0.63 & 0.67 & 1 & & \\
\hline & technology & 9 & 0.13 & 1,79 & 0.78 & 0.65 & 0.71 & 0.64 & 1 & \\
\hline \multirow[t]{3}{*}{ M4 "contents 2D" } & & & & & & & living & physical/te & hnology & \\
\hline & living & 30 & 0.39 & 1,49 & 0.79 & 0.31 & 1 & & & \\
\hline & physical/technology & 22 & 0.38 & 1,50 & 0.63 & 0.46 & 0.74 & 1 & & \\
\hline \multicolumn{11}{|l|}{ M5 "all items 1D" } \\
\hline & total & 52 & 0.38 & 1,40 & 0.77 & 0.26 & 1 & & & \\
\hline
\end{tabular}




\begin{tabular}{lcccc}
\hline Model & log Likelihood & \# parameters & N & BIC \\
\hline M1 "contexts 4D" & -434849 & 776 & 25476 & 877572 \\
M2 "contents 4D" & -434263 & 776 & 25476 & 876400 \\
M3 "contents 3D" & -437975 & 277 & 25476 & 878761 \\
M4 "contents 2D" & -442709 & 178 & 25476 & 887225 \\
M5 "all items 1D" & -450253 & 160 & 25476 & 902129 \\
\hline
\end{tabular}




\begin{tabular}{lcc}
\hline Model & Items with low fit & $\begin{array}{c}\text { Slopes model: } \\
\text { Items with low fit }\end{array}$ \\
\hline M1 "contexts 4D" & 17 & 9 \\
M2 "contents 4D" & 11 & 6 \\
M3 "contents 3D" & 11 & 3 \\
M4 "contents 2D" & 9 & 0 \\
M5 "all items 1D" & 10 & 0 \\
\hline
\end{tabular}




\begin{tabular}{ccccc}
\hline Model & log Likelihood & \# parameters & N & BIC \\
\hline M1 "contexts 4D", 2PL & -432178 & 824 & 25476 & 872716 \\
M2 "contents 4D", 2PL & -431975 & 824 & 25476 & 872311 \\
M3 "contents 3D", 2PL & -434798 & 326 & 25476 & 870249 \\
M4 "contents 2D", 2PL & -438746 & 228 & 25476 & 879805 \\
M5 "all items 1D", 2PL & -444458 & 210 & 25476 & 891046 \\
\hline
\end{tabular}




\begin{tabular}{|c|c|c|c|c|c|}
\hline & \multicolumn{4}{|c|}{ Interest profiles in \% } & \multirow[b]{2}{*}{ Ratio } \\
\hline & $\begin{array}{l}\text { living } \mathbb{I} \\
\text { phys./tech }\end{array}$ & $\begin{array}{l}\text { living } \mathbb{I} \\
\text { phys./tech }\end{array}$ & $\begin{array}{l}\text { living } \\
\text { phys./tech. }\end{array}$ & 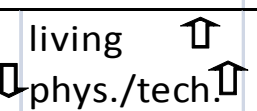 & \\
\hline Finland & 63.7 & 9.9 & 6.7 & 19.8 & 0.67 \\
\hline Canada & 53.8 & 8.8 & 9.1 & 28.3 & 1.03 \\
\hline Japan & 36.1 & 10.4 & 8.4 & 45.1 & 0.81 \\
\hline New Zealand & 57.8 & 7.2 & 9.6 & 25.4 & 1.33 \\
\hline Australia & 56.3 & 8.3 & 8.9 & 26.5 & 1.07 \\
\hline The Netherlands & 64.4 & 8.5 & 8.4 & 18.6 & 0.98 \\
\hline Korea & 47.7 & 9.3 & 10.3 & 32.7 & 1.10 \\
\hline Germany & 36.3 & 10.7 & 10.0 & 43.0 & 0.94 \\
\hline United Kingdom & 56.8 & 8.6 & 8.3 & 26.3 & 0.96 \\
\hline Czech Republic & 46.5 & 8.6 & 11.1 & 33.9 & 1.29 \\
\hline Switzerland & 40.1 & 10.3 & 11.0 & 38.7 & 1.07 \\
\hline Austria & 38.3 & 12.3 & 9.9 & 39.5 & 0.80 \\
\hline Belgium & 41.8 & 8.6 & 11.5 & 38.1 & 1.33 \\
\hline Ireland & 49.7 & 10.7 & 9.3 & 30.3 & 0.87 \\
\hline OECD countries & 41 & 9 & 9 & 41 & 1 \\
\hline
\end{tabular}

